\title{
Н.Н. Севастьянов
}

\section{Создание отечественных спутников связи «Ямал» и его бортовых ретрансляционных комплексов}

\author{
Методами системного анализа рассматриваются проблемы, с которыми пришлось столкнуться при создании \\ спутника связи нового поколения «Ямал-100», разработка которого была осуществлена в России в середине \\ 90-х гг. прошлого столетия. Особое внимание уделено описанию технических решений, примененных при раз- \\ работке бортового ретрансляционного комплекса, выполненного для этого спутника специалистами ОАО «Газ- \\ Ком». \\ Ключевые слова: бортовой ретрансляционный комплекс, БРК, спутники связи «Ямал», «Ямал-100», \\ ОАО «Газком». \\ doi: $10.21293 / 1818-0442-2017-20-1-149-153$
}

Первые промышленные образцы спутников связи с активными бортовыми ретрансляторами (бортовыми ретрансляционными комплексами - БРК), пригодными для передачи ТВ и многоканальной телефонной и телекодовой связи, появились практически одновременно у двух стран - космических лидеров того времени - СССР и США.

В СССР это был спутник связи «Молния-1», созданный в ОКБ-1 (ныне РКК «Энергия») под руководством и по инициативе Главного конструктора космических систем С.П. Королева. Спутник «Молния-1» имел БРК одноствольной конфигурации, работающий в L-диапазоне. Для этого спутника была выбрана высокоэллиптическая орбита (ВЭО) наклонением $61^{\circ}$ и периодом обращения 12 ч; спутник на такой орбите $80 \%$ времени мог находиться над территорией Советского Союза, так что для непрерывной связи достаточно было двух-трех спутников. Первый работающий спутник связи был выведен на ВЭО 23 апреля 1965 г. и подтвердил возможность обеспечения дальней космической связи и вещания ТВ по всей территории СССР.

Политика США по спутниковой связи была сформулирована в послании Президента Дж. Кеннеди НАСА в июле 1961 г., ее суть состояла в том, что США приглашают все страны объединиться для разработки и создания программы коммерческих телекоммуникационных спутников для обеспечения глобальной связи. Инициативные разработки в области космической связи были поддержаны HACA, на их основе компанией Hughes Aircraft coздан спутник Syncom 2, который в июле 1963 г. был выведен на геостационарную орбиту (ГСО). Спутник обеспечивал передачу телефона, телетайпа и факсимильной связи. В этом же году была создана международная компания COMSAT, в которую вошли 11 стран (США, Великобритания, Канада, Япония, Швейцария и др.). Годом позднее, в 1964 г. COMSAT был преобразован в телекоммуникационный спутниковый консорциум INTELSAT. Первый связной спутник, заказанный этим консорциумом компании Hughes, был запущен на геостационарную орбиту 28 июля 1965 г., это был спутник Early Bird-1
INTELSAT 1, обеспечивавший 240 телефонных каналов и 1 канал TV. БРК спутника имел 2-ствольную конфигурацию в С-диапазоне.

Пути развития КА связи главных космических стран-лидеров того времени, СССР и США, заметно отличались. В техническом плане этому способствовали различия в массовых возможностях советского и американского спутников, отличавшихся на порядок вследствие их различных орбит (ВЭО и ГСО) и возможностей средств выведения того времени. Проектная конструкция спутника «Молния-1» и его системы управления обеспечивали постоянную ориентацию большого размера панелей солнечных батарей на Солнце и непрерывную ориентацию на рабочем участке полёта остронаправленных антенн ретранслятора на Землю [1]. Спутник Early Bird I, имел фотоэлементы СБ, расположенные по внешней стороне вращающегося цилиндрического корпуса, при этом эффективность использования полной площади СБ была на уровне 30 \%, что ограничивало энергетические возможности спутника.

В СССР была изначально сделана ставка на КА с БРК повышенной мощности излучения. Транспондеры БРК имели удельную мощность на ствол

40/80 Вт и антенны БРК имели высокую направленность. Последующие модификации спутника «Молния-2» (с 1971 г.), особенно «Молния-3» (с 1974 г., используемая в системе «Интервидение»), имели многоствольные транспондеры высокой мощности с усилителями на лампах бегущей волны (ЛБВ).

Мощность излучения БРК первых КА связи США была на порядок меньше вследствие существенно меньшей располагаемой массы спутника. Однако такая ситуация оказалась временной, и на длительном периоде развития техники космической связи основную роль стали играть долговременные факторы. Основным из них оказалось преимущество ГСО: геостационарный спутник связи неподвижен в земной системе координат, и это обстоятельство сильно упрощает проблему наведения земных остронаправленных антенн на этот спутник. Далее, повышение мощности бортового ретранслятора позво- 
ляет существенно и последовательно уменьшать диаметр наземных антенн, в итоге стало возможным массовое применение малых антенн VSAT индивидуального пользователя. Важным фактором, оказавшим большое влияние на развитие техники спутниковой связи, явилась ее коммерциализация, требование экономической эффективности, предъявляемое ко всем компонентам спутника связи и к наземным ее составляющим, включая терминал конечного пользователя. Это обстоятельство привело к постоянному совершенствованию всех составляющих информационной системы.

Промышленное освоение геостационарной орбиты Советский Союз начал в 1975 г. запуском на ГСО первого геостационарного отечественного спутника «Радуга». На протяжении ряда лет было разработано несколько модификаций этого спутника: «Горизонт», «Экран», «Поток» и другие модели все они использовались исключительно для государственных организаций связи и телевидения. В итоге к концу 90-х гг. оказалось, что отечественные спутники космической связи в техническом и эксплуатационном плане сильно уступают своим западным прототипам по следующим основным параметрам:

- длительность функционирования на орбите (ресурс спутника) была меньше в 3-5 раз;

- мощность электропитания, вырабатываемая служебной платформой КА, - меньше в 3-4 раза;

- количество транспондеров, устанавливаемых на один космический аппарат соизмеримой массы, - меньше в 6-8 раз.

По всем перечисленным выше причинам космическая связь была дорогостоящей, что исключало возможность коммерческого её использования. Появилась угроза потери Россией собственного информационного пространства, так как возникли трудности даже с трансляцией на территорию России государственного телевидения. По сути дела, в это время (середина 90-х гг.) вопрос о спутниковых телекоммуникациях стоял таким образом: или Россия сумеет выйти на мировой уровень в производстве и использовании связных спутников, или ей придется пойти по пути стран третьего мира, заказывающих спутниковые телекоммуникационные услуги у развитых стран Запада.

Разработка отечественного спутника связи «Ямал» была инициирована компанией ОАО «Газком», созданной северными предприятиями газовой отрасли в целях обеспечения связью своих подразделений, осуществлявших производственную деятельность на удаленных территориях РФ. В предисловии научного редактора В.Н. Бранца к монографии «Бортовой ретрансляционный комплекс (БРК) спутника связи. Принципы работы, построение, параметры» сказано, что детальная проектная проработка создаваемого спутника показала, что необходимо сосредоточиться на таких принципиальных вопросах:

использование негерметичной легкой конструкции корпуса и других деталей спутника с применением композитных материалов;

создание бортового ретрансляционного устройства с высоким коэффициентом полезного действия, высокой энергетикой в приемлемых весах для увеличения числа транспондеров на космическом аппарате;

- использование высокоточной надежной системы управления ориентации антенн ретранслятора на Землю и точного удержания спутника в точке стояния с применением инерционных маховиков и электрореактивных двигателей;

- применение высокоэффективных солнечных батарей и аккумуляторных батарей для обеспечения энергоснабжения спутника;

- применение современного бортового вычислительного комплекса для обеспечения полностью цифрового управления спутником и его бортовыми системами;

- достижение длительного ресурса работы спутника на орбите. В качестве первого шага была поставлена задача получения ресурса в 10 лет.

Последнее требование длительного ресурса работы аппаратуры в условиях негерметичной платформы стало критическим. Оно относилось ко всем системам спутника. Оказалось, что, несмотря на длительный период производства спутников связи в стране, такой аппаратуры, к примеру, инерционных маховиков, ЦВМ, электроники, коммутационных элементов и др., просто не существует.

Перед разработчиками нового спутника встала сложнейшая задача. Стало понятно, что решение такой задачи потребует участия в разработке специалистов высшего уровня компетенции. Такое условие и определило в конечном итоге кооперацию работ, сложившуюся по разработке и созданию нового спутника связи ОАО «Газком». Основным предприятием по созданию служебной платформы было выбрано РКК «Энергия», к созданию бортового ретрансляционного комплекса (БРК) были привлечены специалисты МНИИРС (основной организации по созданию бортовых ретрансляторов). Ввиду того, что предприятие МНИИРС, как и большинство остальных предприятий, находилось в то время в глубоком кризисе, «Газкому» пришлось взять эту задачу на себя. С помощью структуры «совместного предприятия» удалось подключить к проекту таких опытных специалистов, как А.Г. Орлов, В.И. Могучев, А.И. Сигал и др. К работам были привлечены также и лидирующие западные компании, такие как SSL, NEC. В итоге была осуществлена разработка бортового ретрансляционного комплекса для первого спутника «Ямал-100» и создан коллектив разработчиков БРК для последующих изделий. По всем остальным составляющим разработки спут- 
ника также были привлечены квалифицированные специалисты [2].

Приведем краткое описание основных технических решений, позволивших группе специалистовсоздателей промышленного БРК спутника «Молния-З» выполнить разработку первого БРК нового поколения для КА «Ямал-100».

Все предшествующие советские и российские БРК гражданского назначения были построены по типу БРК, использованных в первом промышленном советском КА связи «Молния-З», в основе которого лежит построение СВЧ-приемопередатчика (транспондера) по супергетеродинному принципу. При этом СВЧ-сигнал преобразуется в частоты ПЧ (промежуточной частоты 70-100 МГц), усиливается на этих частотах, далее преобразуется в выходные
СВЧ частоты транспондера. Усилители мощности были построены на ЛБВ с КПД 25-30\% (ЛБВ лампы бегущей волны).

Недостатком этой схемы являются: большой объем приемного и маломощного оборудования, повышенный расход массы, энергетики, габаритов платформы и электрорадиоэлементов на один транспондер. Отсюда, прежде всего, и вытекали несопоставимые с мировыми показателями такие характеристики БРК как количество стволов, ресурс, удельные энергомассовые характеристики транспондеров.

Учитывая вышесказанное, при создании БРК «Ямал-100» была выбрана принципиально новая схема построения БРК, показанная на рис. 1.

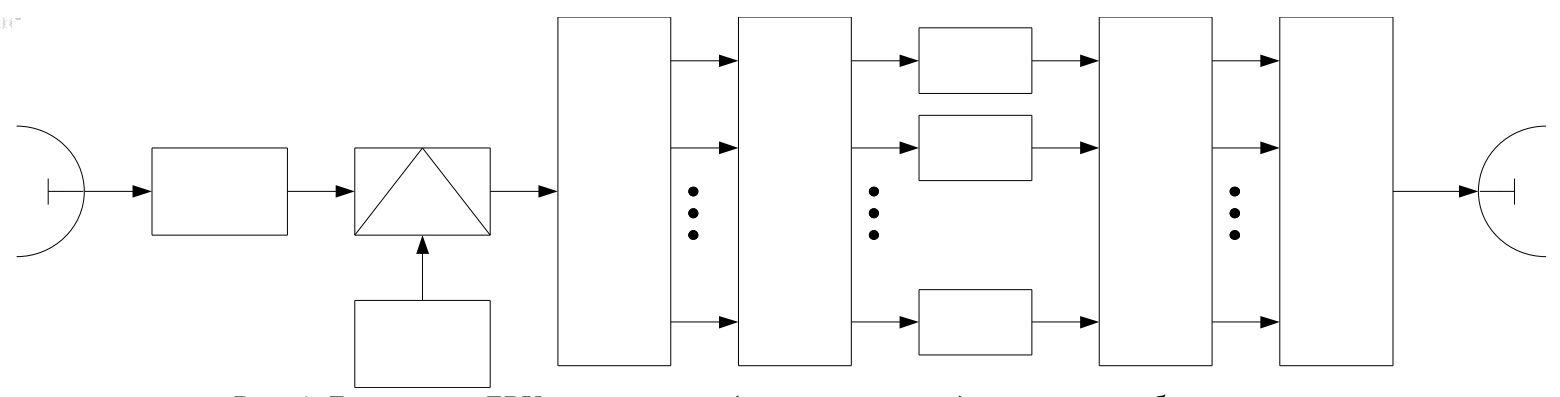

Рис. 1. Блок-схема БРК с $n$-стволами (транспондерами) с одним преобразованием со скользящим резервированием УМ (m:n)

Особенностью этой схемы является использование общего (одного на несколько) широкополосного приемного устройства, содержащего малошумящий усилитель (МШУ) и один преобразователь на разностную частоту сдвига между частотами приема и передачи. Формирование частотных стволов осуществляется фильтровыми многоканальными СВЧмультиплексорами: входными для частотного разделения стволов, принимаемых приемным антеннофидерным устройством АФУ, и выходными с целью их объединения для передачи через передающее АФУ. Практическая реализация БРК по указанной схеме дала колоссальный выигрыш по массе, габаритам, энерогопотреблению, стабильности частоты (из-за того, что преобразователь частоты, в отличие от супергетеродинного построения, работает на более низких частотах сдвига 2-3 ГГц) и привела к улучшению функциональных передаточных характеристик БРК (неравномерности амплитудно-частотной характеристики АЧХ, линейности фазовых характеристик БРК, избирательности, фазовой стабильности гетеродинов). В этой схеме существенно (на порядок) снижено количество активных электрорадиоэлементов (ЭРИ) на транспондер, что явилось одним из факторов повышения надежности и ресурса.

Поскольку в приведенной схеме усиление сигналов в БРК осуществляется по СВЧ, то ключевым моментом ее реализации является коэффициент усиления выходного усилителя мощности, который должен составлять порядка 70-75 дБ. Одиночные ЛБВ имеют усиление порядка 40 дБ, поэтому в каче- стве усилителя мощности были выбраны твердотельные усилители СВЧ, с выходной мощностью в насыщении порядка 30 Вт с КПД порядка $35 \%$, способные к тому же выдавать в линейном режиме мощность порядка 20 Вт (что было важно для применения в наиболее распространенных в коммерческих сетях связи системах многостанционного доступа с частотным разделением каналов).

Структурно-функциональная схема БРК на КА «Ямал-100», соответствующая принципам построения, показанным на рис. 1, представлена на рис. 2. Рассмотренная схема относится к построению важнейшей радиоэлектронной подсистемы БРК - ретранслятору (РТР). Другой подсистемой БРК является АФУ. АФУ БРК «Ямал-100» (разработанное и изготовленное головным предприятием по разработке КА - РКК «Энергия») является оригинальной.

Антенны (приемная и передающая, см. рис. 3) формируют квазиконтурную диаграмму направленности (ДН), максимально согласованную с зоной обслуживания (3О). Конфигурация ДН осуществлялась на параболических зеркалах с помощью кластерного многолучевого облучателя (из 7 парциальных лучей) и диаграммообразующей схемы. Такой подход широко используется и в настоящее время при построении контурных антенн в зарубежных системах подвижной связи (Inmarsat, Garuda, Turaya) и фиксированной связи (системы связи Ка-диапазона).

При создании БРК «Ямал-100» был принципиально изменен порядок выбора компонентов. В качестве компонентов использовались блоки, выполненные на базе микроэлектронных технологий и 
ЭРИ, соответствующие космическим стандартам США и Европы и выпускаемые зарубежными фирмами, такими как NEC (Япония), Alcatel (Франция) и др. Указанные блоки при изготовлении подвергались повышенным наземным испытаниям, соответствующим орбитальным условиям эксплуатации (механическим, тепловым, электромагнитным, электростатическим, радиационным).

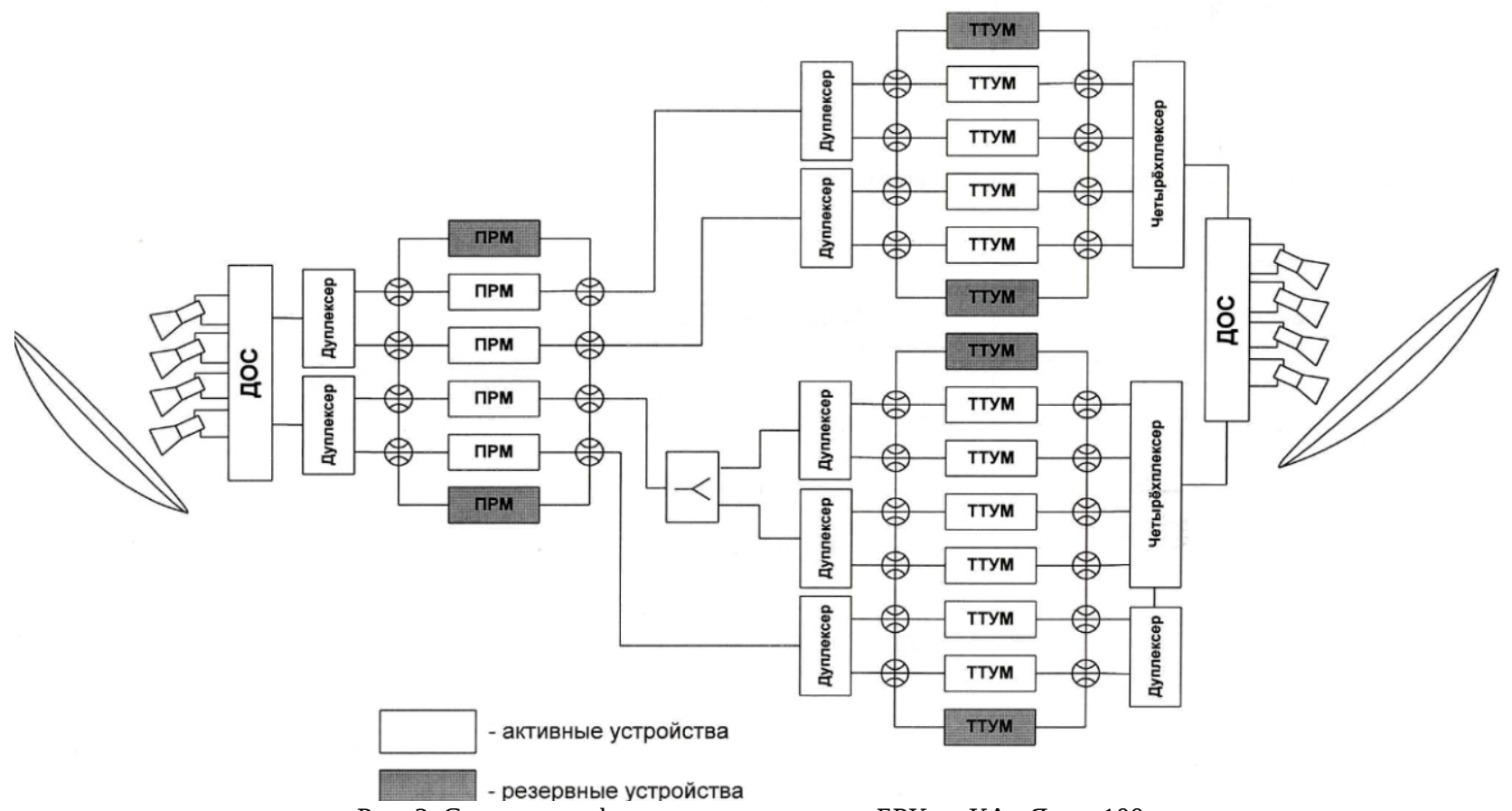

Рис. 2. Структурно-функциональная схема БРК на КА «Ямал-100»

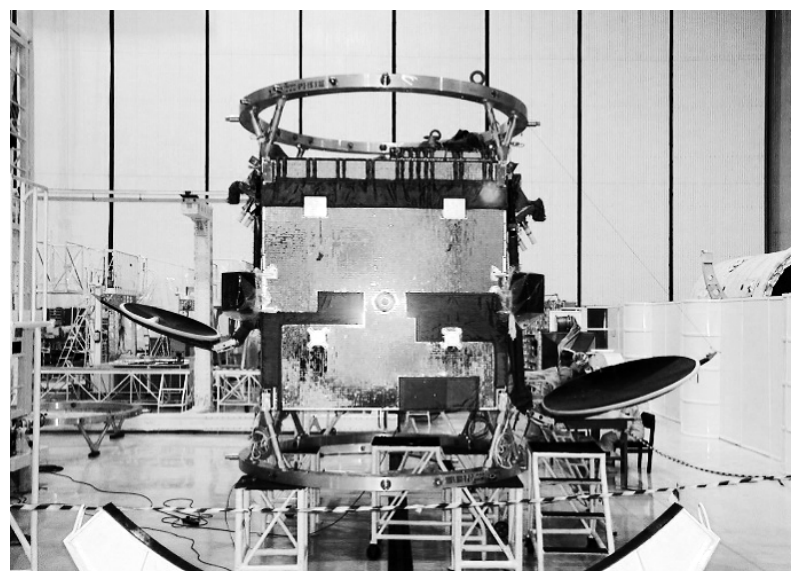

Рис. 3. Антенная система КА «Ямал-100»

Следует отметить важнейшую особенность БРК «Ямал-100»: его аппаратура впервые в отечественной практике целиком функционировала в условиях открытой (негерметичной) платформы. При этом были решены задачи по предотвращению статических и динамических разрядов в устройствах СВЧ РТР и АФУ, работающих при высоких напряженностях электромагнитного поля. При создании БРК «Ямал-100» максимальные усилия были приложены для обеспечения его надежности и ресурса.

Обеспечению требуемого ресурса (не менее 10 лет) способствовала реализация следующих мероприятий: выбранная схемотехника, специальный выбор компонентов, повышенные требования к квалификации компонентов (наличие наземной и летной квалификации), участие разработчиков БРК на всех этапах разработки документации и производства оборудования на предприятиях, в том числе зарубежных. При разработке БРК были тщательно выбраны и рассчитаны схемы резервирования. Впер-

вые в отечественной практике были разработаны эффективные и экономные методы «скользящего» резервирования усилителей мощности на базе высоконадежных импортных СВЧ-переключателей, в частности, реализовано резервирование усилителей мощности 5:1. Для отечественных БРК обычным было резервирование усилителей мощности 2:1 (на базе ферритовых переключателей).

В ходе разработки БРК «Ямал-100» был проведен ряд важных научно-технических работ по особенностям работы БРК, таких как:

- оценка влияния работы плазмы двигателей СПД на работу РТР (на его шумовые характеристики). Работа выполнялась с участием ученых коллективов РАН, кафедр МФТИ, МАИ;

- вопросы возникновения мультипакторных (по отечественной терминологии резонансных) разрядов, пассивных интермодуляционных помех (PIM) в трактах СВЧ с высокими напряженностями электрических полей. Физика этих процессов изложена в монографии [2];

- влияние пониженных давлений на работу электрорадиооборудования БРК.

Исходя из изложенного, можно утверждать, что создание БРК «Ямал-100» (см. рис. 2) - это прорыв- 
ной этап в производстве полезных нагрузок отечественных КА, поскольку:

1) впервые в России был создан для коммерческого использования многоствольный (на 10 стволов) БРК с ресурсом 10 лет с функционированием вне гермоконтейнера;

2) впервые отработана новая схемотехника, принципы использования импортной комплектации, новые подходы к обеспечению ресурса и надежности, новые принципы наземной отработки;

3) впервые полученные функциональные характеристики (частотные, фазовые, линейности, стабильности частоты, паразитных шумов и т.д.) соответствовали мировым стандартам;

4) впервые в отечественную инженерную практику введены и реализованы специальные требования к оборудованию БРК по устойчивости к разрядам в условиях пониженных давлений (газовым, мультипакторным), PIM;
5) впервые на принципах МЛА реализованы контурные ДН антенн;

6) впервые освоена и применена в отечественной практике система мировых стандартов по проектированию, производству, контролю качества полезных нагрузок KA.

6 сентября 1999 г. спутник связи «Ямал-100» был запущен на ГСО. Летные испытания и успешная эксплуатация спутника «Ямал-100» в течение 10 лет полностью подтвердили функциональные, надежностные и ресурсные характеристики БРК.

Сравнительные данные параметров отечественных БРК, иллюстрирующие новизну принятых решений, представлены в таблице. Следует учитывать при этом, что масса КА «Ямал-100» примерно в два раза меньше массы КА «Горизонт».

Развитие отечественных технологий БРК

\begin{tabular}{|c|c|c|c|}
\hline \multirow{2}{*}{ Параметры БРК } & \multicolumn{3}{|c|}{ Тип КА } \\
\cline { 2 - 4 } & Молния-3 & Горизонт & \multicolumn{1}{c|}{ Ямал-100 } \\
\hline Год запуска & 1974 & 1978 & С \\
\hline Диапазон частот & $\mathrm{C}$ & $\mathrm{C}, \mathrm{Ku}$ & 10 \\
\hline Количество стволов (транспондеров) & 3 & 7 & 36 \\
\hline Рабочая полоса транспондера, МГц & 40 & 34,40 & 1300 \\
\hline Энергопотребление, Вт & 900 & 1000 & 41 \\
\hline ЭИИМ (макс.), дБВт & 30 & $28-46$ & 10 \\
\hline Ресурс, лет & 3 & 3 & \\
\hline
\end{tabular}

Схемотехнические и структурно-функциональные решения, впервые использованные при создании «Ямал-100», были далее успешно применены при создании БРК «Ямал-200» и «Ямал-300» [2]. Разработка БРК «Ямал-100» была выполнена ОАО «Газком».

\section{Лuтература}

1. Бранец В.Н. Лекции по теории систем ориентации, управления движением и навигации: учеб. пособие / В.Н. Бранец, Н.Н. Севастьянов, Р.В. Федулов. - Томск: Изд-во Том. ун-та, 2013. - 310 с.

2. Орлов А.Г. Бортовой ретрансляционный комплекс (БРК) спутника связи. Принципы работы, построение, параметры: учеб. пособие / А.Г. Орлов, Н.Н. Севастьянов; науч. ред. В.Н. Бранец. - Томск: Изд-во Том. гос. ун-та, 2014. - 206 c
Севастьянов Николай Николаевич

Канд. техн. наук, ген. конструктор

ОАО «Газпром космические системы»

Тел.: 8 (495) 504-29-03

Эл. почта: info@gazprom-spacesystems.ru

Sevastiyanov N.N.

Creation of Domestic Communication Satellites «Yamal» and its Onboard Repeaters

Using system analysis methods, this paper handles the challenges faced during the production and development of a new generation communication satellite Yamal-100 in the mid 90's of the last century. The special focus is given to the description of technical solutions implemented when developing a satellite onboard repeater designed by JSC Gascom experts.

Keywords: onboard repeater, communication satellites «Yamal», «Yamal-100», JSC Gascom. 